\title{
Geographic Variations of Potentially Curative Treatments for Hepatocellular Carcinoma in the United States: A SEER-Medicare Study
}

\author{
En Cheng, MD, MSPH${ }^{1}$; Peiyin Hung, MSPH, $\mathrm{PhD}^{2,3}$; and Shi-Yi Wang, MD, PhD ${ }^{1,4}$
}

\section{ABSTRACT}

Background: Transplantation, surgical resection, radiofrequency ablation, and percutaneous ethanol injection are generally considered potentially curative treatments for patients with hepatocellular carcinoma ( $\mathrm{HCC})$. With the increasing incidence of $\mathrm{HCC}$, it is critical to investigate geographic variations in curative treatments and their associations with survival among patients. Methods: A total of 6,782 patients with HCC during 2004 to 2011 were identified in the SEER-Medicare linked database and placed in quartiles based on the proportions undergoing potentially curative treatments per hospital referral region (HRR). Hierarchical Cox proportional hazards models were used to examine the association between regional potentially curative treatment patterns and survival across quartiles. Results: An average of $16.9 \%$ of patients with HCC underwent potentially curative treatments during 2004 to 2011, varying substantially from $0 \%$ to $34.5 \%$ across HRRs. Compared with patients residing in the lowest-quartile regions, those in the highest-quartile regions were more likely to be of other races (vs white or black), be infected with hepatitis $B$ virus, and have more comorbidities. The 5 -year survival was $4.7 \%$ in the lowest-quartile regions and $11.4 \%$ in the highestquartile regions $(P<.001)$. After controlling for confounders, patients in the highest-quartile regions had a lower risk of mortality (adjusted hazard ratio, $0.78 ; 95 \% \mathrm{Cl}, 0.72-0.85)$. Conclusions: Patients with HCC who resided in HRRs with higher proportions of potentially curative treatments had better survival. Given its proven survival benefits, prompt clinical and policy actions are needed to reduce variations in treatment utilization.

J Natl Compr Canc Netw 2020;18(6):729-736 doi: $10.6004 /$ jnccn.2020.7529

\footnotetext{
${ }^{1}$ Department of Chronic Disease Epidemiology, School of Public Health, Yale University, New Haven, Connecticut; ${ }^{2}$ Department of Health Services Policy and Management, Arnold School of Public Health, University of South Carolina, and ${ }^{3}$ Rural and Minority Health Research Center, Columbia, South Carolina; and ${ }^{4}$ Cancer Outcomes, Public Policy, and Effectiveness Research Center, Yale Cancer Center, New Haven, Connecticut.
}

\section{Background}

Hepatocellular carcinoma (HCC) is the dominant histologic type of liver cancer, affecting approximately 20,000 Americans annually. ${ }^{1}$ HCC incidence and mortality have been increasing in the United States during the past 3 decades. $^{2}$ Evidence-based HCC management guidelines have been updated to take full advantage of current treatment options, including transplantation, surgical resection, radiofrequency ablation (RFA), percutaneous ethanol injection (PEI), transarterial chemoembolization (TACE), and chemotherapy. ${ }^{3-6}$ Many studies have reported beneficial effects of these options-in particular, transplantation, surgical resection, RFA, and PEI are considered potentially curative treatments because these interventions can markedly improve survival among patients with early-stage HCC. ${ }^{7-10}$

Despite the proven benefits of HCC interventions, geographic disparities persist in the use of potentially curative treatments. ${ }^{11,12}$ Across states, for instance, patients in California, New Mexico, and Georgia have been less likely to receive potentially curative treatments. ${ }^{12-14}$ In addition, geographic variation in HCC survival exists. Literature has suggested that patients with HCC in southern states have worse survival than those in nonsouthern states. ${ }^{14}$ However, no study has linked the use of potentially curative treatments to HCC survival at the regional level. Because hospital referral regions (HRRs) represent regional healthcare resources where most potentially curative treatments may be given, investigating HRR-level geographic variations in HCC curative treatments and their associations with survival may help identify treatment needs, guide public health resource allocations, and improve HCC outcomes.

Accordingly, we first investigated geographic variation in the proportions of potentially curative treatments among patients with HCC across HRRs. We further

See JNCCN.org for supplemental online content. 
compared HCC survival across HRRs by the level of potentially curative treatment use and how patient demographics, tumor characteristics, and comorbidities were associated with survival among patients with HCC.

\section{Methods}

\section{Data Source and Population}

We established a population-based retrospective cohort study using the SEER-Medicare linked database. The SEER program is an authoritative source of information on cancer incidence and survival in the United States and covers approximately $34.6 \%$ of the US population via population-based cancer registries. ${ }^{1}$ Medicare is a national health insurance program in the United States that covers individuals aged $\geq 65$ years and those aged $<65$ years with special needs. ${ }^{15}$ The SEER-Medicare linked dataset contains demographic, clinical, and cause-of-death information and the Medicare claims for covered healthcare services from the time of a person's Medicare eligibility (mostly for those aged $\geq 65$ years) until death. ${ }^{16}$ The Yale University Institutional Review Board approved this study, which did not directly involve human subjects.

We identified patients aged $\geq 66$ years with HCC diagnosed in January 2004 through December 2011, with follow-up to the end of 2013. Patients were included if their source of diagnosis was not death certificate or autopsy, they had continuous fee-for-service Medicare Part A or B coverage from 1 year before diagnosis through either death or 6 months after HCC diagnosis, and they had a known ZIP code of residence to be linked to the HRRs. We did not exclude patients with PO Box addresses because their number $(n=159)$ was small $(2.3 \%)$ and sensitivity analyses reached similar conclusions after excluding them (see supplemental eTable 1, available with this article at JNCCN.org). Originally HRRs were developed by the Dartmouth Atlas of Healthcare to evaluate regional healthcare markets for tertiary medical care. ${ }^{17}$ Each HRR contains a minimum population of 120,000 and at least 1 hospital that performs major cardiovascular procedures and neurosurgery, and the residents of each HRR must receive at least $65 \%$ of their hospitalization within the HRR. There are 306 HRRs in the United States, and their boundaries may cross state borders. To reduce variability caused by low HRR volumes, we excluded data from HRRs with $<10$ patients during the study period and included 84 HRRs in the study.

\section{Treatment Strategies}

Using the Healthcare Common Procedure Coding System codes, we classified and prioritized treatment into 6 categories: (1) transplantation, a surgical procedure providing excellent survival outcomes ${ }^{18}$; (2) surgical resection, a procedure achieving a high rate of complete response in properly selected patients ${ }^{18,19}$; (3) RFA or PEI, an alternative option for patients with early-stage HCC not eligible for resection ${ }^{7,9,10}$; (4) TACE, an image-guided, nonsurgical palliative procedure providing survival benefits for patients with intermediate-stage $\mathrm{HCC}^{9}$; (5) chemotherapy or targeted therapy, a palliative treatment providing marginal improvements of survival of patients with advanced-stage $\mathrm{HCC}^{8}$; and (6) no treatment, if patients received none of these treatments. We defined potentially curative treatment as consisting of transplantation, surgical resection, RFA, and PEI, because these options can improve the natural history of the disease, markedly prolonging the survival of patients with early-stage HCC regardless of their age. ${ }^{7-10,18}$ However, patients with stage IV HCC may still benefit from these treatments. ${ }^{20-23}$ Because patients whose disease stage is unknown may constitute those diagnosed at different stages (I, II, III, and IV), they could also benefit from potentially curative treatment. Thus, we did not exclude patients with stage IV disease or whose stage was unknown. We created a dichotomous indicator to assess whether each patient had any of the potentially curative treatments within 6 months of diagnosis.

We calculated the proportion of patients undergoing potentially curative treatments for each HRR and then classified HRRs into quartiles, with quartile 1 representing the HRRs of the lowest proportion and quartile 4 the highest. Each quartile accounted for one-fourth of the HRRs in our sample.

\section{Covariates}

Patient characteristics included the demographics of the study population (age at diagnosis, sex, race, and marital status), cancer stage, and comorbidities. The 6th edition of the AJCC Cancer Staging Manual was used for classifying tumor stage, as reported in SEER. The Elixhauser comorbidity index was used to measure patient comorbidity, ${ }^{24}$ encoding the top 3 diagnoses at clinical visits and the top 5 diagnoses at hospitalization in the SEER-Medicare database. Furthermore, the diagnosis of hepatitis B virus infection (HBV; ICD-9 codes 070.2, 070.3, V02.62), hepatitis C virus infection (HCV; ICD-9 codes 070.41, 070.44, 070.51, 070.54, 070.70, 070.71, V02.62), alcohol-related liver disease (ARLD; ICD-9 codes 571.0, 571.1, 571.2, 571.3), or cirrhosis (ICD-9 codes 571.2, $571.5,571.6,571.8,571.9)$ was defined as being identified in 1 inpatient or 1 outpatient claim in the 12 months before HCC diagnosis.

\section{Statistical Analysis}

We used $t$ tests for continuous variables and chi-square tests for categorical variables to compare differences in 
demographic data and clinical data between the highest and lowest quartiles. In addition, we used a one-way analysis of variance to estimate overall differences in age across the 4 quartiles. Geographic disparities of potentially curative treatments by HRR were mapped and displayed using ArcGIS software (Esri).

Kaplan-Meier estimates were calculated and plotted to compare the survival of patients with HCC by quartile versus the proportions of potentially curative treatments. Hierarchical Cox proportional hazards regression with patients clustered within HRRs and states was used to calculate adjusted hazard ratios (aHRs) and 95\% confidence intervals to estimate the association of the proportions of potentially curative treatment (quartiles) with survival. The proportional hazards assumption was evaluated using the method of Schoenfeld residuals. Criteria for covariate inclusion in the regression model were biological plausibility and/or whether inclusion/ exclusion of the variable from the model changed the aHR for the primary exposure variable by $\geq 10 \%$; thus, the final regression model included the following variables: age at diagnosis (ages 66-69, 70-74, $75-79,80-84, \geq 85$ years), race (white, black, other), marital status (married, unmarried, other), locale (metropolitan, nonmetropolitan), cancer stage (I, II, III, IV, unknown), Elixhauser comorbidity index $(0,1-2, \geq 3)$, HBV, HCV, ARLD, and cirrhosis.

All analyses were conducted using SAS 9.4 (SAS Institute, Inc.) and ArcGIS (Esri). A 2-sided $P$ value $<.05$ was considered statistically significant.

\section{Results}

Our sample consisted of 6,782 patients with HCC with a follow-up time of 9,235 person-years (median, 7.1 months). Approximately $90 \%$ of these patients died by the end of follow-up. The mean proportion of patients with HCC undergoing potentially curative treatments was $16.9 \%$. The proportion differed substantially, ranging from $0 \%$ in the Paterson-Hackensack (New Jersey) areas to $34.5 \%$ in the Paducah (Kentucky) area. Interestingly, the proportion of potentially curative treatments not only varied by state but also varied substantially across HRRs within a state (Figure 1). For instance, HRRs in California, Louisiana, Michigan, and New Jersey spanned all quartiles.

The median proportion of patients undergoing potentially curative treatments from the lowest-quartile areas to the highest-quartile areas was $6.7 \%$ (range, 0\%-10.8\%), 13.5\% (11.1\%-16.2\%), 17.4\% (16.3\%-20.0\%), and $24.5 \%(20.8 \%-34.5 \%)$, respectively. Patient characteristics differed between the highest and lowest

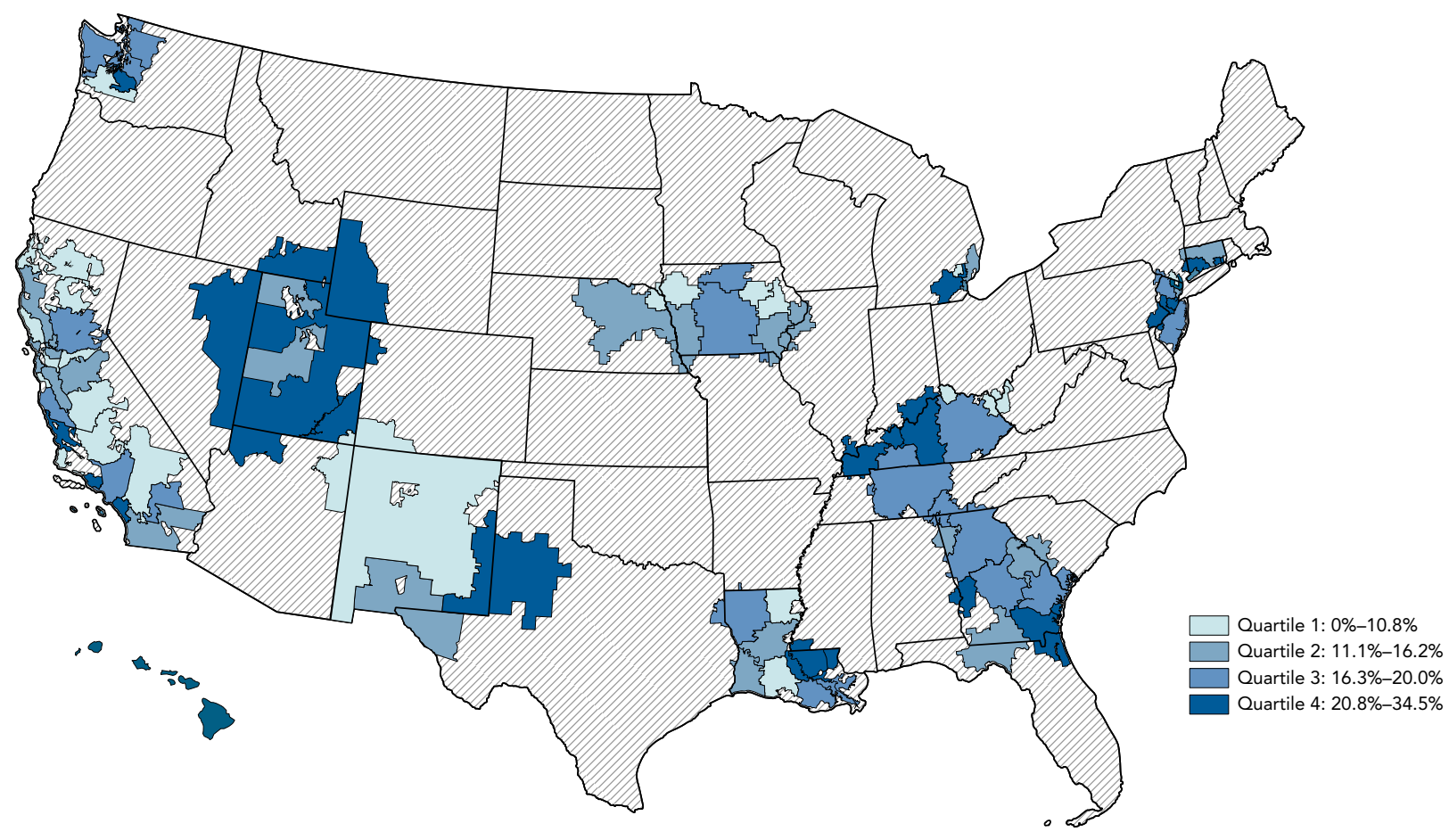

Figure 1. Quartiles of unadjusted proportions by HRR of patients diagnosed with HCC in 2004 through 2011 undergoing potentially curative treatments. HRRs with $\geq 10$ patients with $\mathrm{HCC}$ who received the treatments in the SEER registry sites were included.

Abbreviations: HCC, hepatocellular carcinoma; HRR, hospital referral region. 
HRR-level quartiles (Table 1). Patients living in the highestutilization regions relative to the lowest-utilization regions were more likely to be of other races (vs white or black), be married, have HBV, have higher Elixhauser comorbidity index scores, and live in metropolitan areas, yet there was no statistically significant difference in HCC stage distribution between the highest- and lowest-utilization regions. Age did not differ statistically significantly between the highest and lowest HRR-level quartiles $(P=.58)$ or across quartiles $(P=.93)$. Differences in treatment

\section{Table 1. Patient Characteristics}

Potentially Curative Treatment by HRR-Level Quartile

\begin{tabular}{|c|c|c|c|c|c|}
\hline Characteristic & $\begin{array}{c}1 \\
(0 \%-10.8 \%)\end{array}$ & $\stackrel{2}{2}$ & $\begin{array}{c}3 \\
(16.3 \%-20.0 \%)\end{array}$ & $\begin{array}{c}4 \\
(20.8 \%-34.5 \%)\end{array}$ & $\begin{array}{l}P \text { Value } \\
\text { Q1 vs Q4 }\end{array}$ \\
\hline Mean age (SD), y & $75.4 \pm 6.7$ & $75.5 \pm 6.7$ & $75.5 \pm 6.5$ & $75.5 \pm 6.4$ & .58 \\
\hline Men & $648(64.9)$ & $1,089(64.9)$ & $1,786(67.4)$ & $937(64.4)$ & .77 \\
\hline Race & & & & & $<.01$ \\
\hline White & $785(78.7)$ & $1,101(65.6)$ & $1,910(72.1)$ & $1,038(71.3)$ & \\
\hline Black & $68(6.8)$ & $190(11.3)$ & $212(8.0)$ & $89(6.1)$ & \\
\hline Other & $145(14.5)$ & $387(23.1)$ & $528(19.9)$ & $329(22.6)$ & \\
\hline Marital status & & & & & .01 \\
\hline Married & $515(51.6)$ & $880(52.4)$ & $1,451(54.8)$ & $838(57.6)$ & \\
\hline Unmarried & $446(44.7)$ & $749(44.6)$ & $1,079(40.7)$ & $571(39.2)$ & \\
\hline Other & $37(3.7)$ & $49(2.9)$ & $120(4.5)$ & $47(3.2)$ & \\
\hline Urban/Rural continuum ${ }^{a}$ & & & & & $<.01$ \\
\hline Metropolitan & $829(83.1)$ & $1,480(88.2)$ & $2,346(88.5)$ & $1,316(90.4)$ & \\
\hline Nonmetropolitan & $169(16.9)$ & $198(11.8)$ & $304(11.5)$ & $140(9.6)$ & \\
\hline Prior physician visit ${ }^{b}$ & $903(90.5)$ & $1,511(90.1)$ & $2,416(91.2)$ & $1,332(91.5)$ & .39 \\
\hline Elixhauser comorbidity index & & & & & .03 \\
\hline 0 & $284(28.5)$ & $533(31.8)$ & $763(28.8)$ & $430(29.5)$ & \\
\hline $1-2$ & $443(44.4)$ & $653(38.9)$ & $1,125(42.5)$ & $571(39.2)$ & \\
\hline$\geq 3$ & $271(27.1)$ & $492(29.3)$ & $762(28.8)$ & 455 (31.3) & \\
\hline Tumor size, $\mathrm{cm}$ & & & & & .06 \\
\hline$\leq 2.0$ & $49(4.9)$ & $115(6.9)$ & $188(7.1)$ & $99(6.8)$ & \\
\hline 2.1 to $\leq 5.0$ & $259(25.9)$ & $502(29.9)$ & $738(27.9)$ & $416(28.6)$ & \\
\hline 5.1 to $\leq 10.0$ & $284(28.5)$ & $423(25.2)$ & $691(26.1)$ & $404(27.8)$ & \\
\hline$\geq 10.1$ & $129(12.9)$ & $233(13.9)$ & $356(13.4)$ & $192(13.2)$ & \\
\hline Other/Missing & $277(27.8)$ & $405(24.1)$ & 677 (25.9) & $345(23.7)$ & \\
\hline Cancer stage & & & & & .09 \\
\hline I & $333(33.4)$ & $541(32.2)$ & $786(29.7)$ & 475 (32.6) & \\
\hline$\|$ & $114(11.4)$ & $234(14.0)$ & $362(13.7)$ & $192(13.2)$ & \\
\hline III & $173(17.4)$ & $352(21.0)$ & $512(19.3)$ & $299(20.5)$ & \\
\hline IV & $158(15.8)$ & $245(14.6)$ & $375(14.2)$ & $196(13.5)$ & \\
\hline Unknown & $220(22.0)$ & $306(18.2)$ & $615(23.2)$ & $294(20.2)$ & \\
\hline Hepatitis B virus infection ${ }^{c}$ & $30(3.0)$ & $142(8.5)$ & $218(8.2)$ & $92(6.3)$ & $<.01$ \\
\hline Hepatitis $C$ virus infection ${ }^{c}$ & 209 (20.9) & $412(24.6)$ & $593(22.4)$ & $321(22.1)$ & .51 \\
\hline Alcohol-related liver disease ${ }^{c}$ & $118(11.8)$ & $175(10.4)$ & $251(9.5)$ & $146(10.0)$ & .16 \\
\hline Cirrhosis $^{b}$ & $325(32.6)$ & $596(35.5)$ & $947(35.7)$ & $501(34.4)$ & .34 \\
\hline
\end{tabular}

Abbreviations: HCC, hepatocellular carcinoma; HRR, hospital referral region.

aClassification of "metropolitan" and "nonmetropolitan" was based on 2003 rural/urban continuum codes from the Economic Research Service, U.S. Department of Agriculture.

bisited physicians in the 12 months before or after diagnosis.

cldentified in 1 inpatient or 1 outpatient claim in the 12 months before HCC diagnosis. 


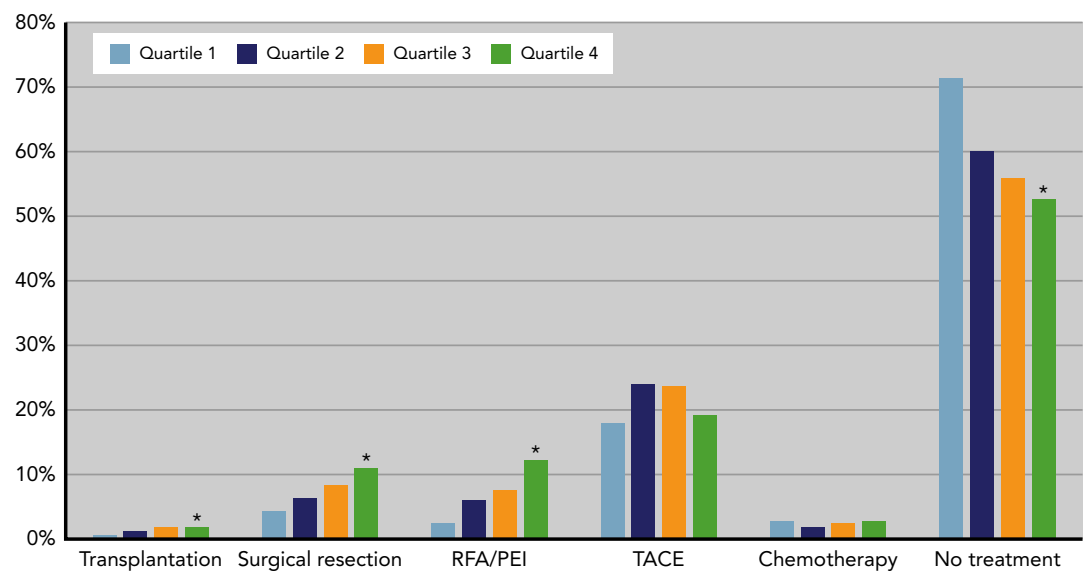

Figure 2. Treatment patterns across HRR-level quartiles.

Abbreviations: HRR, hospital referral region; PEI, percutaneous ethanol injection; RFA, radiofrequency ablation; TACE, transarterial chemoembolization.

${ }^{\star} P<.01$ between quartile 1 and quartile 4 .

patterns across quartiles are presented in Figure 2. Although the proportions of patients undergoing transplantation in the lowest- and highest-utilization regions were very low, they differed statistically significantly $(P<.01)$. Similarly, $4.5 \%$ and $2.5 \%$ of patients in the lowestutilization regions received surgical resection and RFA/PEI, respectively, but the corresponding proportions for the highest-utilization regions were $11.1 \%$ and $12.3 \%$.

Median survival was 5.2, 7.7, 7.1, and 8.0 months for the first, second, third, and fourth HRR-level quartiles, respectively. Patients who resided in the highest-quartile areas had better survival than those who resided in the lowest-quartile areas (log-rank $P<.01$; Figure 3 ). The proportional hazards assumption for survival was satisfied across quartile areas using the method of Schoenfeld residuals. Controlling for potential confounders, we found that the quartile indicator was independently associated with survival (Table 2). Compared with patients in the lowest quartile, those in the highest quartile of taking potentially curative treatment were statistically significantly associated with having a lower risk of mortality (HR, 0.78; 95\% CI, 0.72-0.85). Patients in the second and third quartiles also had a significantly lower risk of mortality (both $P$ values <.01). Older age, black race, unmarried status, advanced or unknown cancer stage, higher Elixhauser comorbidity index scores $(\geq 3)$, and ARLD were also significantly associated with a higher risk of mortality, but HBV, HCV, and cirrhosis were significantly associated with lower mortality. Sensitivity analyses using population number to classify HRRs into quartiles reached similar results (supplemental eTable 2).

\section{Discussion}

Prior literature has shown geographic variation in HCC incidence and survival in the United States. ${ }^{14,25}$ Several studies have also found substantial geographic variation in HCC treatment patterns. ${ }^{11,25}$ Although researchers have raised the concern of underuse of potentially curative treatments, ${ }^{11}$ no study has related management patterns with survival at the region level. To our knowledge, this is the first study to show that patients with HCC residing in areas with high use of potentially curative treatments had better survival than those residing in lowutilization areas, after controlling for clinical and tumorrelated features. Given that the mortality rate of liver cancer is increasing despite a decrease in mortality from most cancer types in the United States, ${ }^{26}$ strategies for increasing appropriate treatment use are urgently needed.

Our findings build on prior work in important ways. First, the results indicate that underuse of potentially curative treatments is a systemwide issue because the patterns observed persisted across all 3 potentially curative treatments-transplantation, surgical resection,

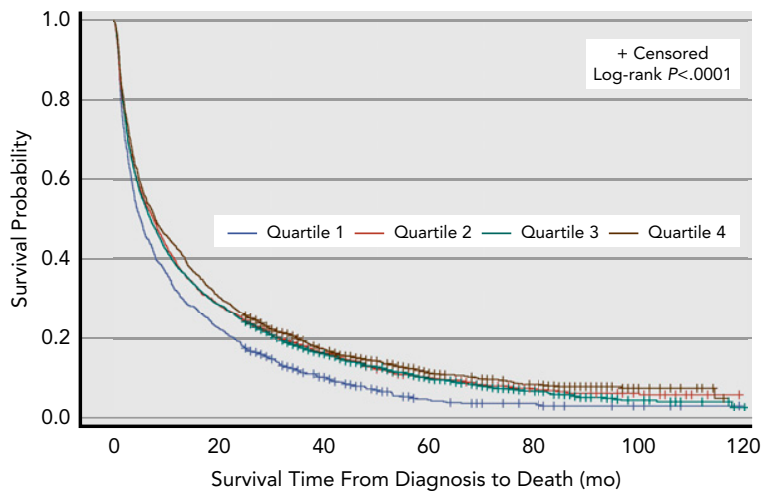

Figure 3. Kaplan-Meier estimates of survival by HRR-level quartile of potentially curative treatments.

Abbreviation: HRR, hospital referral region. 


\section{Table 2. Adjusted HRs of Mortality}

\begin{tabular}{|c|c|c|}
\hline & Adjusted HR (95\% Cl) & $P$ Value \\
\hline \multicolumn{3}{|l|}{ HRR level } \\
\hline First quartile & Ref & \\
\hline Second quartile & $0.84(0.78-0.92)$ & $<.01$ \\
\hline Third quartile & $0.85(0.79-0.92)$ & $<.01$ \\
\hline Fourth quartile & $0.78(0.72-0.85)$ & $<.01$ \\
\hline \multicolumn{3}{|l|}{ Age, y } \\
\hline $66-69$ & Ref & \\
\hline $70-74$ & $1.11(1.03-1.19)$ & $<.01$ \\
\hline $75-79$ & $1.21(1.12-1.31)$ & $<.01$ \\
\hline $80-84$ & $1.33(1.22-1.44)$ & $<.01$ \\
\hline$\geq 85$ & $1.55(1.40-1.71)$ & $<.01$ \\
\hline \multicolumn{3}{|l|}{ Race } \\
\hline White & Ref & \\
\hline Black & $1.16(1.06-1.27)$ & $<.01$ \\
\hline Other & $0.83(0.77-0.89)$ & $<.01$ \\
\hline \multicolumn{3}{|l|}{ Marital status } \\
\hline Married & $\operatorname{Re}$ & \\
\hline Unmarried & $1.15(1.09-1.21)$ & $<.01$ \\
\hline Other & $1.06(0.92-1.21)$ & .42 \\
\hline \multicolumn{3}{|l|}{ Cancer stage } \\
\hline I & Ref & \\
\hline ॥ & $1.04(0.95-1.13)$ & .38 \\
\hline III & $1.94(1.80-2.09)$ & $<.01$ \\
\hline IV & $3.46(3.18-3.76)$ & $<.01$ \\
\hline Unknown & $2.32(2.15-2.49)$ & $<.01$ \\
\hline \multicolumn{3}{|l|}{ Elixhauser comorbidity index } \\
\hline 0 & Ref & \\
\hline $1-2$ & $1.01(0.95-1.07)$ & .76 \\
\hline$\geq 3$ & $1.28(1.20-1.37)$ & $<.01$ \\
\hline Hepatitis B virus infectiona & $0.68(0.60-0.76)$ & $<.01$ \\
\hline Hepatitis $C$ virus infection ${ }^{a}$ & $0.88(0.82-0.94)$ & $<.01$ \\
\hline Alcohol-related liver disease ${ }^{a}$ & $1.15(1.05-1.27)$ & $<.01$ \\
\hline Cirrhosis $^{a}$ & $0.90(0.84-0.96)$ & $<.01$ \\
\hline Living in metropolitan counties ${ }^{b}$ & $0.96(0.88-1.03)$ & .26 \\
\hline
\end{tabular}

Abbreviations: $\mathrm{HCC}$, hepatocellular carcinoma; HR, hazard ratio; HRR, hospital referral region.

aldentified in 1 inpatient or 1 outpatient claim in the 12 months before HCC diagnosis.

"Classification of "metropolitan" and "nonmetropolitan" was based on 2003 rural/urban continuum codes from the Economic Research Service, US Department of Agriculture.

and local ablation. In addition, the absolute difference between the highest- and the lowest-quartile areas in the proportion of patients undergoing transplantation was only approximately $1 \%$. Although transplantation offers the best chance for survival, it may not be available because of limited liver donors. ${ }^{27}$ Thus, increasing transplantation rates across all quartile areas would be challenging. In contrast, the absolute difference in the proportion of patients undergoing surgical resection and local ablation was substantial, approximately $7 \%$ and $10 \%$, respectively, suggesting room for improvement. Policymakers could develop a program, either financial incentives or quality improvement, to increase the use of surgical resection and local ablation among eligible patients, especially in low-utilization areas.

Second, compared with prior literature, our findings indicate an increase in the use of local ablation and TACE over time. When analyzing SEER-Medicare data from 1994 through 1999, researchers found that approximately $9 \%$ of patients with HCC underwent transplantation or surgical resection, $4 \%$ underwent local ablation, and $4 \%$ underwent TACE. ${ }^{11}$ Our study, using the same data source but from 2004 through 2011, found a similar proportion of patients undergoing transplantation or surgical resection, yet $8 \%$ and $22 \%$ of patients underwent local ablation and TACE, respectively. Future research exploring the reason why the lowest-utilization areas had an increase in TACE use may help promote appropriate treatments. Although substantial geographic variation in local ablation existed, we were surprised that the lowest- and highest-utilization areas had similar proportions of patients undergoing TACE ( $18.1 \%$ and $19.3 \%$, respectively; $P=.47$ ). A plausible explanation may be that the providers in the highest-utilization areas avoided the suboptimal treatment strategy of TACE by promoting potentially curative treatments.

Third, we found not only interstate variation but also within-state variation. At the state level, $<10 \%$ of patients in New Mexico received potentially curative treatments during the study period compared with $28.5 \%$ of patients in Hawaii. New Mexico, the fifth largest state in the United States, has slightly more than 2 million people, and most people live in sparsely populated areas given the expansive geography. As of 2018, 97\% of New Mexico's 33 counties were marked as health professional shortage areas. ${ }^{28}$ Even worse, New Mexico has the lowest high school graduation rate among all states and ranks 47 th for its economic stability. ${ }^{29}$ These provider shortages and socioeconomic disadvantages may lead to treatment utilization disparities. In contrast, $>66 \%$ of Hawaii residents live on Oahu, 1 of 8 major islands in Hawaii, which may make it easier for patients with early-stage HCC to access potentially curative treatments. ${ }^{30}$ Furthermore, there was substantial variation in treatment patterns within states. Factors associated with access to appropriate care, such as urban residence and high socioeconomic status, may contribute to a higher proportion of patients undergoing potentially curative treatments in HRRs even within the same state. For instance, California, Louisiana, Michigan, and New Jersey have a high population density with a wide and 
diverse mix of people, ${ }^{30}$ and apparent variation existed within each state.

We also found several factors associated with worse survival. Consistent with prior literature, black race, unmarried status, older age, cancer at an advanced stage, comorbidities, and ARLD were associated with worse survival. ${ }^{11,14,31,32}$ Although HBV or HCV and the presence of cirrhosis are generally considered to damage liver function, the associations between these factors and survival are still inconclusive. ${ }^{33-35}$ Our findings showed that HBV or HCV and cirrhosis were significantly associated with better survival, which may be potentially explained by the benefits of early detection through screening. For instance, patients with liver-related comorbidities may be more likely to undergo surveillance and receive potentially curative treatment when HCC is diagnosed. One study analyzing SEER-Medicare data reported that patients with HCC who had chronic $\mathrm{HBV}$, chronic HCV, or nonalcoholic cirrhosis were more likely to undergo potentially curative treatments. ${ }^{36}$

Our study has several limitations. First, our analyses were based on the Medicare fee-for-service population residing in SEER regions. Thus, our results do not necessarily represent all Medicare beneficiaries. Generalization to younger patients or patients enrolled in other insurance plans is limited. However, based on SEER cancer statistics, ${ }^{1}>58 \%$ of patients with HCC were aged $\geq 65$ years and $>89 \%$ were aged $\geq 55$ years (2012-2016), and Medicare provided health insurance for $>59.9$ million individuals in 2018 ( $\geq 51$ million people aged $\geq 65$ years and approximately 8 million younger individuals), ${ }^{37}$ and therefore we believe that our findings could be generalizable to larger populations and regions. Second, other factors known to impact long-term survival are lacking, such as HCC etiology, liver function, degree of portal hypertension, underlying disease states, functional status, chemotherapy, and cancer recurrences. Although we used claims data to measure $\mathrm{HBV} / \mathrm{HCV}$, cirrhosis, and comorbidities, we acknowledge that these indicators are subject to measurement errors. Third, the SEER-Medicare database did not provide information about treatments that physicians recommended and patients opted to undergo. Finally, the use of chemotherapy was underestimated, because parts of the cohort preceded the approval of sorafenib for HCC, and because we prioritized potentially curative treatments and TACE before chemotherapy. However, this underestimation did not impact our conclusions given the palliative nature of sorafenib.

\section{Conclusions}

This analysis provided comprehensive data on regionallevel variation in HCC treatment patterns and its associations with survival. Our findings showed that treatment patterns for HCC vary substantially in the United States. Furthermore, patients with HCC residing in HRRs with lower proportions of patients undergoing potentially curative treatments had worse survival. Efforts to implement appropriate treatment would benefit from focusing on the use of surgical resection and local ablation, especially in low-utilization areas.

Submitted October 16, 2019; accepted for publication January 6, 2020.

Author contributions: Study concept: Cheng, Wang. Data analysis: Cheng, Hung. Manuscript preparation: Cheng, Hung. Critical revision: Hung, Wang. Study supervision: Cheng, Wang.

Disclosures: Dr. Wang has disclosed that he receives grant/research support from Genentech. The remaining authors have disclosed that they have not received any financial consideration from any person or organization to support the preparation, analysis, results, or discussion of this article.

Correspondence: En Cheng, MD, MSPH, Department of Chronic Disease Epidemiology, School of Public Health, Yale University, 60 College Street, New Haven, CT 06510. Email en.cheng@yale.edu

\section{References}

1. Noone AM, Howlader N, Krapcho M, et al, eds. SEER Cancer Statistics Review, 1975-2015, National Cancer Institute. Bethesda, MD. Available at: https://seer.cancer.gov/csr/1975_2015/, based on November 2017 SEER data submission, posted to the SEER web site, April 2018. Accessed March 31, 2020.

2. White DL, Thrift AP, Kanwal F, et al. Incidence of hepatocellular carcinoma in all 50 United States, from 2000 through 2012. Gastroenterology 2017; 152:812-820.e5.

3. Bruix J, Reig M, Sherman M. Evidence-based diagnosis, staging, and treatment of patients with hepatocellular carcinoma. Gastroenterology 2016;150:835-853.

4. European Association for the Study of the Liver. EASL clinical practice guidelines: management of hepatocellular carcinoma. J Hepatol 2018;69: 182-236.

5. Heimbach JK, Kulik LM, Finn RS, et al. AASLD guidelines for the treatment of hepatocellular carcinoma. Hepatology 2018;67:358-380.

6. Fong ZV, Tanabe KK. The clinical management of hepatocellular carcinoma in the United States, Europe, and Asia: a comprehensive and evidence-based comparison and review. Cancer 2014;120: 2824-2838
7. Cho YK, Kim JK, Kim MY, et al. Systematic review of randomized trials for hepatocellular carcinoma treated with percutaneous ablation therapies. Hepatology 2009;49:453-459

8. Lin S, Hoffmann K, Schemmer P. Treatment of hepatocellular carcinoma: a systematic review. Liver Cancer 2012;1:144-158.

9. Llovet JM, Bruix J. Systematic review of randomized trials for unresectable hepatocellular carcinoma: chemoembolization improves survival. Hepatology 2003;37:429-442.

10. Simonetti RG, Liberati A, Angiolini C, et al. Treatment of hepatocellular carcinoma: a systematic review of randomized controlled trials. Ann Onco 1997;8:117-136.

11. El-Serag HB, Siegel AB, Davila JA, et al. Treatment and outcomes of treating of hepatocellular carcinoma among Medicare recipients in the United States: a population-based study. J Hepatol 2006;44:158-166.

12. Sonnenday CJ, Dimick JB, Schulick RD, et al. Racial and geographic disparities in the utilization of surgical therapy for hepatocellular carcinoma. J Gastrointest Surg 2007;11:1636-1646.

13. Altekruse SF, Henley SJ, Cucinelli JE, et al. Changing hepatocellular carcinoma incidence and liver cancer mortality rates in the United States. Am J Gastroenterol 2014;109:542-553. 
14. Franco RA, Fan $Y$, Jarosek $S$, et al. Racial and geographic disparities in hepatocellular carcinoma outcomes. Am J Prev Med 2018;55(Suppl 1): S40-48.

15. Gornick ME, Warren JL, Eggers PW, et al. Thirty years of Medicare: impact on the covered population. Health Care Financ Rev 1996;18:179-237.

16. Warren JL, Klabunde CN, Schrag D, et al. Overview of the SEER-Medicare data: content, research applications, and generalizability to the United States elderly population. Med Care 2002;40(8 Suppl):IV-3-18.

17. Dartmouth Atlas Project. Understanding geographic variations in health care. Accessed October 9, 2019. Available at: http://www.dartmouthatlas.org

18. Llovet JM, Schwartz M, Mazzaferro V. Resection and liver transplantation for hepatocellular carcinoma. Semin Liver Dis 2005;25:181-200.

19. Tsuzuki T, Sugioka A, Ueda M, et al. Hepatic resection for hepatocellular carcinoma. Surgery 1990;107:511-520.

20. Chirica M, Scatton O, Massault PP, et al. Treatment of stage IVA hepatocellular carcinoma: should we reappraise the role of surgery? Arch Surg 2008; 143:538-543.

21. Hanazaki K, Kajikawa S, Shimozawa N, et al. A 15-year retrospective study of hepatic resection for stage IV-A hepatocellular carcinoma shows value in hepatitis B negative patients. Am J Surg 2002;183:89-94.

22. Poon RT, Fan ST, Ng IO, et al. Prognosis after hepatic resection for stage IVA hepatocellular carcinoma: a need for reclassification. Ann Surg 2003; 237:376-383

23. Shimada M, Takenaka K, Kawahara N, et al. Surgical treatment strategy for patients with stage IV hepatocellular carcinoma. Surgery 1996;119: 517-522.

24. Elixhauser A, Steiner C, Harris DR, et al. Comorbidity measures for use with administrative data. Med Care 1998;36:8-27.

25. Islami F, Miller KD, Siegel RL, et al. Disparities in liver cancer occurrence in the United States by race/ethnicity and state. CA Cancer J Clin 2017;67: 273-289.

26. Cronin KA, Lake AJ, Scott $S$, et al. Annual report to the nation on the status of cancer, part I: national cancer statistics. Cancer 2018;124:2785-2800.
27. Lauerer M, Kaiser K, Nagel E. Organ transplantation in the face of donor shortage: ethical implications with a focus on liver allocation. Visc Med 2016;32:278-285.

28. New Mexico Department of Health. The State of Health in New Mexico 2018. Accessed October 9, 2019. Available at: https://nmhealth.org/ publication/view/report/4442/

29. U.S. News \& World Report. Best States 2019. Accessed October 9, 2019 Available at: https://www.usnews.com/news/best-states/

30. United States Census Bureau. Population and Housing Unit Estimates. Accessed October 9, 2019. Available at: https://www.census.gov/programs-surveys/popest.html

31. Aizer AA, Chen $\mathrm{MH}, \mathrm{McC}$ arthy $\mathrm{EP}$, et al. Marital status and survival in patients with cancer. J Clin Oncol 2013;31:3869-3876.

32. Galati G, Dell'Unto C, Vespasiani-Gentilucci U, et al. Hepatocellular carcinoma in alcoholic liver disease: current management and recent advances. Rev Recent Clin Trials 2016;11:238-252.

33. Kuo KL, Stenehjem D, Albright F, et al. Treatment patterns and outcomes in patients with hepatocellular carcinoma stratified by stageguided treatment categories. J Natl Compr Canc Netw 2015;13: 987-994.

34. Poon RT, Fan ST, Lo CM, et al. Long-term prognosis after resection of hepatocellular carcinoma associated with hepatitis B-related cirrhosis. $\mathrm{J}$ Clin Oncol 2000;18:1094-1101.

35. Chen VL, Le AK, Kim NG, et al. Effects of cirrhosis on short-term and longterm survival of patients with hepatitis B-related hepatocellular carcinoma. Clin Gastroenterol Hepatol 2016;14:887-895.e1.

36. Nathan $\mathrm{H}$, Hyder $\mathrm{O}$, Mayo SC, et al. Surgical therapy for early hepatocellular carcinoma in the modern era: a 10-year SEER-Medicare analysis. Ann Surg 2013;258:1022-1027.

37. Centers for Medicare \& Medicaid Services. 2019 Medicare Trustees Report. Accessed October 9, 2019. Available at: https://www.cms.gov/ Research-Statistics-Data-and-Systems/Statistics-Trends-and-Reports/ ReportsTrustFunds/Downloads/TR2019.pdf 

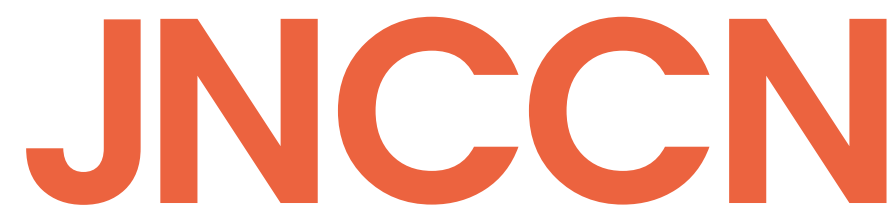

National

Comprehensive

Supplemental online content for:

\section{Geographic Variations of Potentially Curative Treatments for Hepatocellular Carcinoma in the United States: A SEER-Medicare Study}

En Cheng, MD, MSPH; Peiyin Hung, MSPH, PhD; and Shi-Yi Wang, MD, PhD

J Natl Compr Canc Netw 2020;18(6):729-736

eTable 1: Adjusted HRs of Mortality After Excluding Patients With PO Box Addresses

eTable 2: Multivariable-Adjusted Associations With Survival 


\section{eTable 1. Adjusted HRs of Mortality After Excluding Patients With PO Box Addresses $(\mathrm{N}=6,623)$}

\begin{tabular}{|c|c|c|}
\hline & Adjusted HR $(95 \% \mathrm{Cl})$ & $P$ Value \\
\hline \multicolumn{3}{|l|}{ HRR level } \\
\hline First quartile & Ref & \\
\hline Second quartile & $0.85(0.78-0.92)$ & $<.01$ \\
\hline Third quartile & $0.85(0.79-0.92)$ & $<.01$ \\
\hline Fourth quartile & $0.78(0.72-0.85)$ & $<.01$ \\
\hline \multicolumn{3}{|l|}{ Age, y } \\
\hline $66-69$ & Ref & \\
\hline $70-74$ & $1.10(1.02-1.19)$ & .01 \\
\hline $75-79$ & $1.21(1.12-1.31)$ & $<.01$ \\
\hline $80-84$ & $1.34(1.23-1.46)$ & $<.01$ \\
\hline$\geq 85$ & $1.56(1.41-1.72)$ & $<.01$ \\
\hline \multicolumn{3}{|l|}{ Race } \\
\hline White & Ref & \\
\hline Black & $1.17(1.06-1.29)$ & $<.01$ \\
\hline Other & $0.82(0.76-0.88)$ & $<.01$ \\
\hline \multicolumn{3}{|l|}{ Marital status } \\
\hline Married & Ref & \\
\hline Unmarried & $1.15(1.09-1.22)$ & $<.01$ \\
\hline Other & $1.06(0.93-1.22)$ & .38 \\
\hline \multicolumn{3}{|l|}{ Cancer stage } \\
\hline 1 & Ref & \\
\hline$\|$ & $1.05(0.96-1.14)$ & .30 \\
\hline III & $1.95(1.81-2.10)$ & $<.01$ \\
\hline IV & $3.46(3.18-3.76)$ & $<.01$ \\
\hline Unknown & $2.31(2.15-2.49)$ & $<.01$ \\
\hline \multicolumn{3}{|l|}{ Elixhauser comorbidity index } \\
\hline 0 & Ref & \\
\hline $1-2$ & $1.01(0.95-1.08)$ & .74 \\
\hline$\geq 3$ & $1.28(1.19-1.37)$ & $<.01$ \\
\hline Hepatitis $B$ virus infectiona & $0.68(0.61-0.77)$ & $<.01$ \\
\hline Hepatitis $C$ virus infection ${ }^{a}$ & $0.89(0.83-0.95)$ & $<.01$ \\
\hline Alcohol-related liver disease ${ }^{a}$ & $1.17(1.06-1.29)$ & $<.01$ \\
\hline Cirrhosis $^{a}$ & $0.89(0.84-0.95)$ & $<.01$ \\
\hline Living in metropolitan counties ${ }^{b}$ & $0.98(0.90-1.06)$ & .57 \\
\hline
\end{tabular}

Abbreviations: HCC, hepatocellular carcinoma; HR, hazard ratio; HRR, hospital referral region.

aldentified in 1 inpatient or 1 outpatient claim in the 12 months before HCC diagnosis.

bClassification of "metropolitan" and "nonmetropolitan" was based on 2003

rural/urban continuum codes from the Economic Research Service, US

Department of Agriculture.

\section{eTable 2. Multivariable-Adjusted Associations} With Survival

\begin{tabular}{|lcr|}
\hline & HR $(95 \%$ Cl) & P Value \\
\hline Population level & & \\
\hline First quartile & Ref & \\
\hline Second quartile & $0.93(0.86-1.00)$ & .05 \\
\hline Third quartile & $0.92(0.86-0.99)$ & .03 \\
\hline Fourth quartile & $0.85(0.79-0.92)$ & $<.01$ \\
\hline
\end{tabular}

Age, y

\begin{tabular}{lcr}
\hline $66-69$ & Ref & \\
\hline $70-74$ & $1.11(1.03-1.19)$ & $<.01$ \\
\hline $75-79$ & $1.21(1.12-1.30)$ & $<.01$ \\
\hline $80-84$ & $1.32(1.21-1.44)$ & $<.01$ \\
$\geq 85$ & $1.55(1.40-1.71)$ & $<.01$
\end{tabular}

Race

White Ref

\begin{tabular}{lll}
\hline Black & $1.16(1.05-1.27)$ & $<.01$ \\
\hline Other & $0.82(0.76-0.88)$ & $<.01$
\end{tabular}

Marital status

Married Ref

\begin{tabular}{llr}
\hline Unmarried & $1.15(1.09-1.21)$ & $<.01$ \\
\hline Other & $1.06(0.92-1.21)$ & .42
\end{tabular}

Cancer stage

I Ref

II $\quad 1.04(0.95-1.13) \quad .42$

III $\quad 1.93(1.79-2.08) \quad<.01$

IV $3.44(3.17-3.74)<.01$

Unknown $\quad 2.31(2.15-2.49)<.01$

Elixhauser comorbidity index

0 Ref

\begin{tabular}{llr}
\hline $1-2$ & $1.01(0.95-1.07)$ & .64 \\
\hline$\geq 3$ & $1.28(1.20-1.38)$ & $<.01$ \\
Hepatitis B virus infection $^{\mathrm{a}}$ & $0.67(0.60-0.76)$ & $<.01$ \\
Hepatitis C virus infection $^{\mathrm{a}}$ & $0.88(0.82-0.94)$ & $<.01$ \\
Alcohol-related liver disease $^{\mathrm{a}}$ & $1.16(1.05-1.27)$ & $<.01$ \\
Cirrhosis $^{\mathrm{a}}$ & $0.90(0.84-0.95)$ & $<.01$ \\
Living in metropolitan counties $^{\mathrm{a}}$ & $0.96(0.88-1.03)$ & .25
\end{tabular}

Abbreviations: HCC, hepatocellular carcinoma; HR, hazard ratio.

aldentified in 1 inpatient or 1 outpatient claim in the 12 months before $\mathrm{HCC}$ diagnosis.

bClassification of "metropolitan" and "nonmetropolitan" was based on 2003 rural/urban continuum codes from the Economic Research Service, US Department of Agriculture. 